\title{
Contactless Measurement of Metallic Targets by a Specially Designed Position Sensor
}

Prof. Dr.-Ing. Ulrich Kindler,

Fachhochschule Luebeck

Labor Mikromechanik, Aufbau- und Verbindungstechnik, Moenkhofer Weg 239

D-23562 Luebeck

GERMANY

\begin{abstract}
It is a well known technical problem to fix a separate magnet as target for measurement. The innovation of the position sensor presented here is a special geometric form of flat coils which are arranged as a couple. These coils are electrically interconnected to an alternating current half bridge. The metallic target moves over the coils in a non contacting manner and in a defined working distance. The only condition for the target is to be metallic. Of course measuring magnetic targets induce bigger measuring signals. But it is not necessary for the target to be magnetic.

The flat coils produce eddy currents in the metallic target. These eddy currents damp the flat coils.

Caused by the geometric form of the flat coils, the flat coils are damped in the adversary direction. The ac half bridge converts the difference caused by the damping into a voltage signal. The voltage signal is amplified. As a result (after this) the phase is correctly rectified. We get a linear relation between the movement of the target and the output signal. Angle movements can be measured by flat coils which are arranged in a circle. A ferrite plate is fixed on the back of the flat coils. The ferrite plate amplifies the measuring effect and furthermore protects the flat coils against disturbing objects on their backside. With this sensor, moving mechanical components can be measured in an easy way. In addition to this, position sensors can be applied for the identification of coins. The coins have to be moved across the sensor. As a result different coins induce specific characteristic curves. The curve characteristic depends on size and material of the coin. All these results indicate an universal approach to a whole range of applications.
\end{abstract}

\section{Introduction to non contact eddy current sensors}

The main application for eddy current sensors is the measuring of distance. This eddy current sensor consists of a coil which is fed with an alternating current of a frequence in the range 1 up to $2 \mathrm{Mhz}$. At the front edge of the coil the high frequent field leaving the coil has impact to a metal plate. This metal

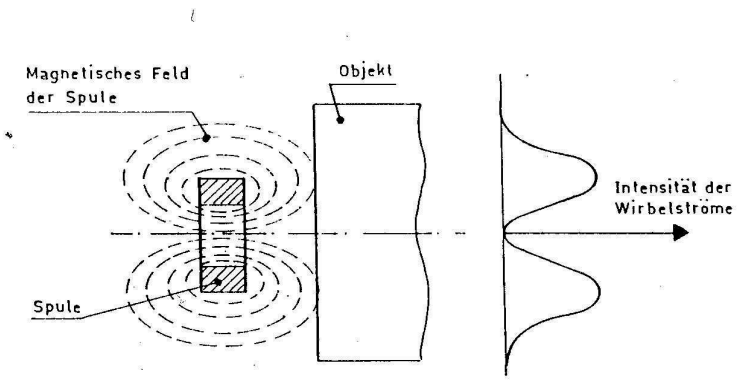

Figur 1: Coil with magnetic field and measuring object [6]

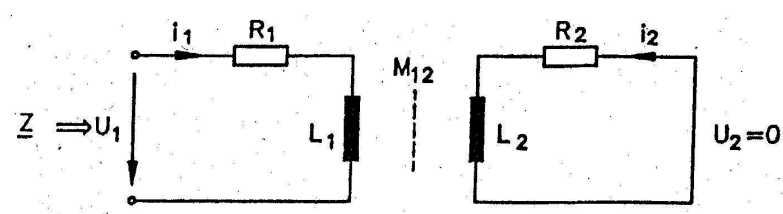

Figur 2: Equivalent circuit of mutual inductance [7] plate, used as a target, has a distance from the front edge of the coil which is used as the measuring distance. In the metal plate eddy currents are induced (figure 1). Following the law of induced voltage these currents are inducing a counter field which causes a damping of the generated if electromagnetic field.

Following figure 2 the current $I_{1}$ in the coil $L_{1}$ generates the if field. The eddy currents in the metal plate propagate as circular short circuit currents. This situation is demonstrated in the equivalent circuit by introducing an inductance $L_{2}$ and a current $\mathrm{I}_{2}$ which are generating the opposite field and which are reducing the inductance $L_{1}$. In case of the metal plate being magnetic there is the magnetostatic effect which gives a rise to the inductance $L_{1}$. $R_{2}$ represents the eddy current losses which produce heat in the ohmic resistance of the metal plate. $U_{2}=0$ explains the short circuit current, be- 
cause there is no other load. The coupling of both fields is done via the mutual inductance $\mathrm{M}_{12}$. As a consequence this principle is modelling a non contact transform coupling between sensor coil and the metal plate which is representing the measuring target (figure 2).

Thefore the equation of the impedance of the coil is given as:

$$
Z=\frac{u_{1}}{i_{1}}=R_{1}+j \omega L_{1}+\frac{\left(R_{2}-j \omega L_{2}\right) \cdot \omega^{2} \cdot M_{12}^{2}}{\left(R_{2}^{2}+\omega^{2} \cdot L_{2}^{2}\right)}
$$

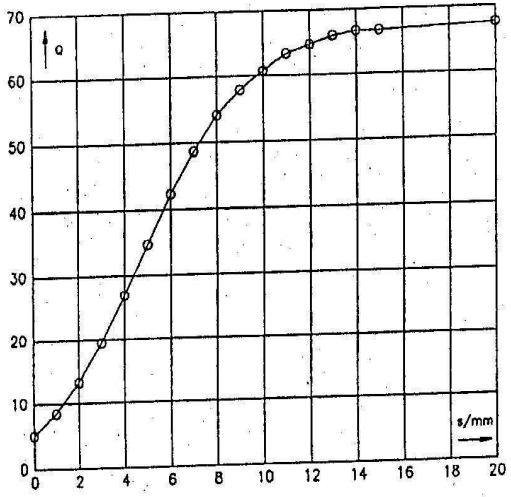

Figur 3: Quality Q dependent on the distance
Dependent on the distance between sensor coil and measuring object the real value of $Z$ is mainly changing as a function of $R_{2}, L_{2}$ and $M_{12}$. The evaluation is done by building up a resonant circuit, i.e. connecting the coil with a capacitor. For small distances the damping of the resonant ciruit is strong and having a small quality $Q$ and on the other side big distances result in high quality $Q$ (figure 3 ). The resonant circuit is fed by an oscillator. The change of distance changes the ratio of damping and finally results in a change of resonance amplitude. This voltage over the resonance circuit is given to a rectifier and then amplified. The range of distances starts with $0 . .1 \mathrm{~mm}$ and ends with $0 . .50 \mathrm{~mm}$. As a thumb rule one can take the measuring range as half the diameter of the coil. For applications in measuring distances usually circular winded coils are used.

\section{Specially designed position sensor}

For all position sensors we use here flat coils which are produced in printed board technology (figure 5a). These flat coils only have a small quality factor $Q$ which for low frequencies is smaller than 1 . In this case the use of a resonance amplitude is not possible (figure 4). Parameter is the thickness of the copper con-

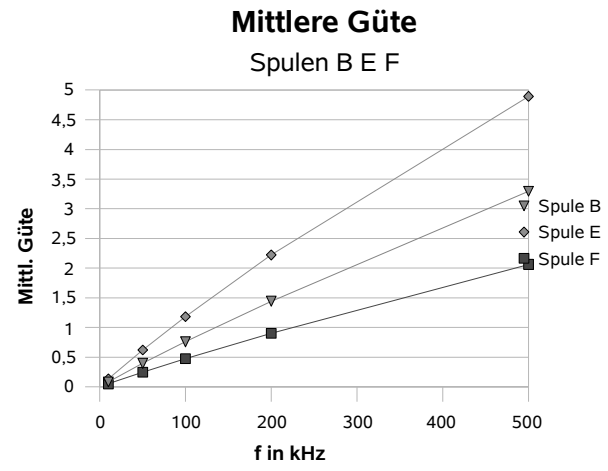

Figur 4: Coil quality $\mathrm{Q}$ dependent on frequency

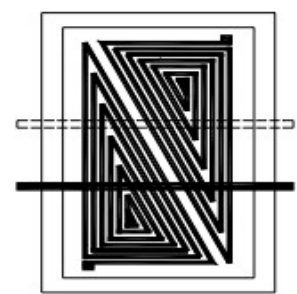

Figur 5: a) Flat Coils with target

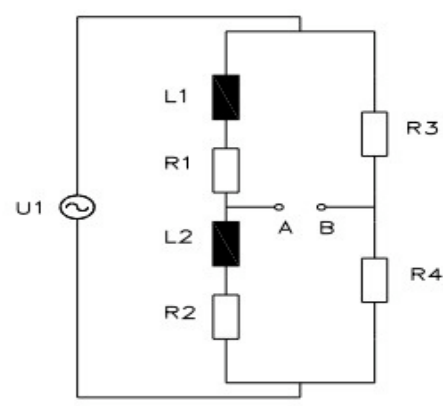

b) Alternating current half bridge

ductor with $\mathrm{F}=18 \mu \mathrm{m}, \mathrm{B}=35 \mu \mathrm{m}, \mathrm{E}=70 \mu \mathrm{m}$. Therefore we are not using a resonant circuit but in this place we do the evaluation with an ac half bridge in differential operation (figure $5 \mathrm{~b}$ ). For applying the right magnitude to this bridge it is necessary to get a coincident change of target $R_{1}$ by $\Delta R_{1}$ together with a change of $L_{1}$ by $\Delta L_{1}$ when the target moves upwards (figure $5 \mathrm{a}$ ). On the other side the corresponding $R_{2}$ should become smaller by $\Delta \mathrm{R}_{2}$ and $\mathrm{L}_{2}$ should be reduced by $\Delta \mathrm{L}_{2}$ in the same process. 
Regarding the position sensor in figure 5 a let the lower position of the target named position 1 and the upper position named position 2 . Then the target in the lower position 1 gives a damping to only a small part of the right flat coil. The flat coil on the left side has a bigger damping. The extent of the damping depends

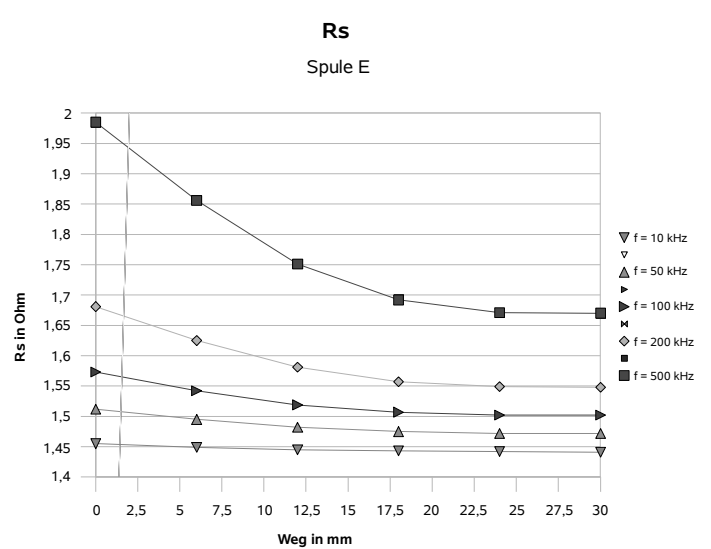

Figur 6: Resistance dependent on the distance (frequency used as parameter)

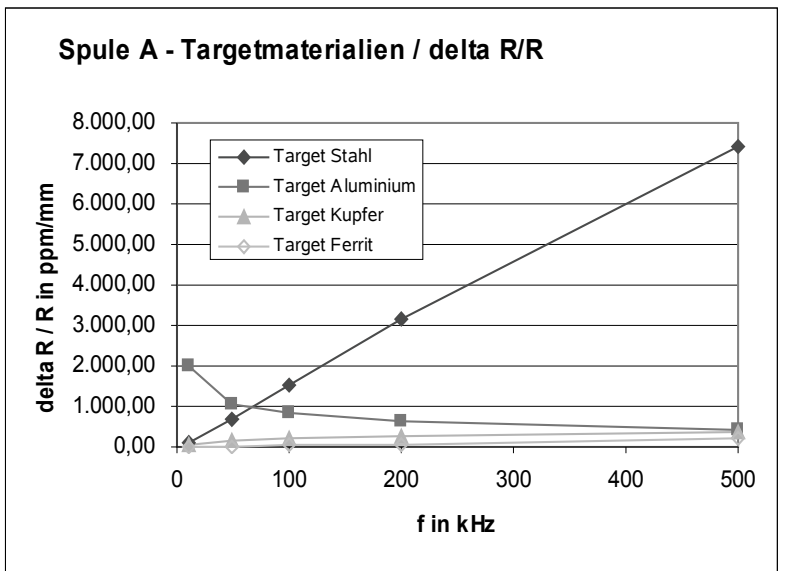

Figur 7: $\Delta R / R$ dependent on the frequency (target materials used as parameter)

on the position of the target. If the target is moved upwards into position 2 the damping in the right coil is extended, which means that we get on the right side a part $+\Delta R_{2}$ and on the left side a part $-\Delta R_{1}$. In figure 6 the characteristic of $R_{1}$ is shown dependent on the distance of an iron target. Parameter is the frequency. It can be seen that for higher frequencies the sensitivity becomes higher but also the nonlinearity is growing. In figure $7 \Delta R / R$ is shown dependent on the frequency.

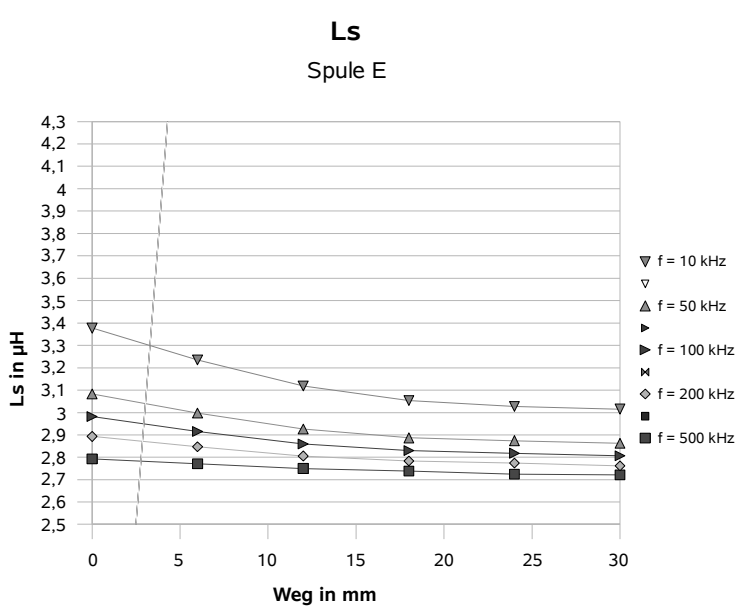

Figur 8: Characteristic of induction dependent on distance

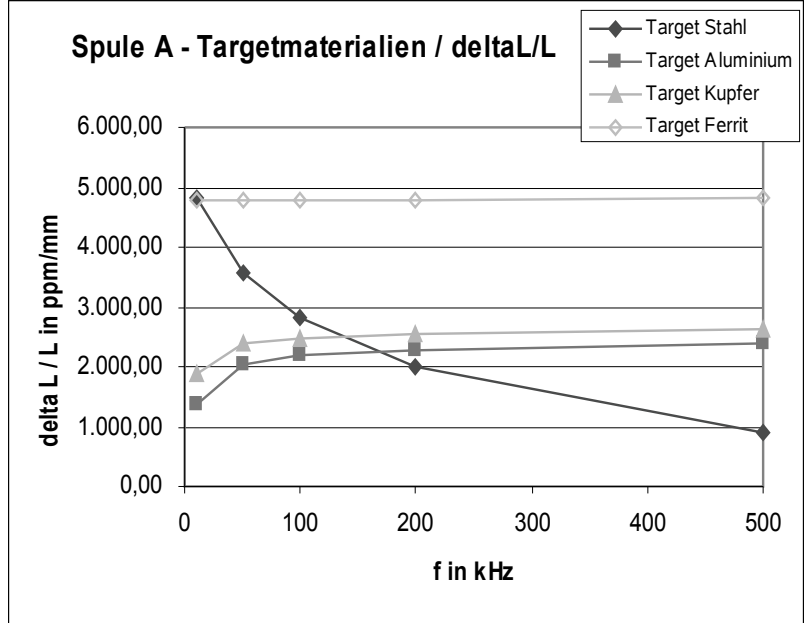

Figur 9: $\Delta \mathrm{L} / \mathrm{L}$ dependent on the frequency

In figure 8 the change of $L_{s}$ dependent on the distance can be seen, also with the frequency given as parameter. In this case the inductance will get the highest change rate at lowest frequencies. In figure $9 \Delta \mathrm{L} / \mathrm{L}$ is given dependent on the frequency.

The characteristics of $\Delta R / R$ und $\Delta L / L$ are dependent on the material, as can be seen from figures 7 and 9. In both diagrams iron offers the highest change rates. 


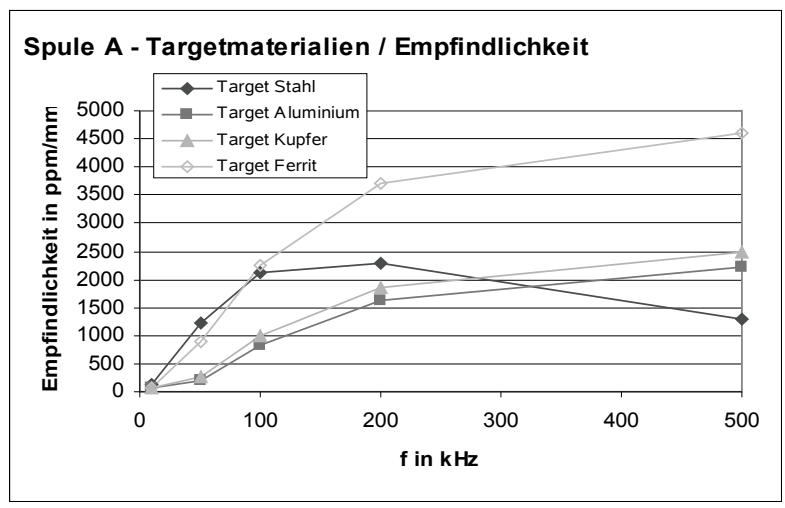

Figur 10: Sensitivity dependent on the frequency

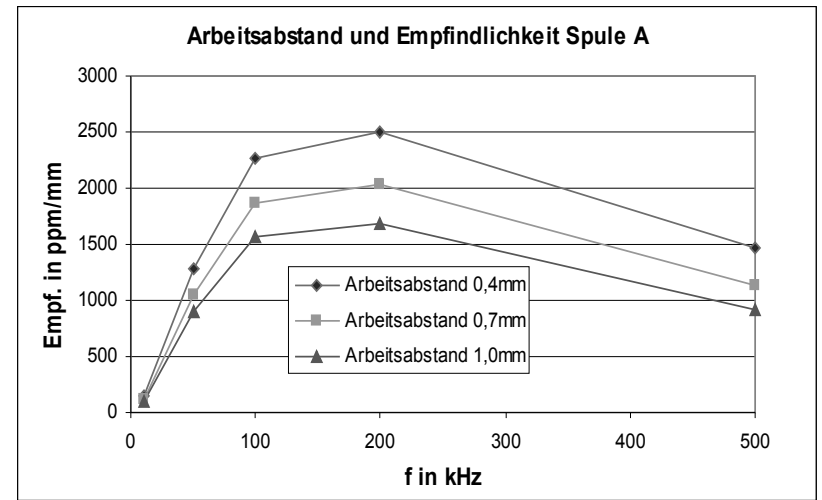

Figur 11: Sensitivity dependent on the frequency (distance used as parameter)

In figure 10 the output voltage ot the ac bridge is shown. The scaling is done as follows. The sensitivity equals the change of voltage against the change of distance. For the iron target one can observe a maximum value of $200 \mathrm{kHz}$, for aluminium and copper target there is no such maximum value. These dependencies afford to calibrate the position sensor to the used target materials.

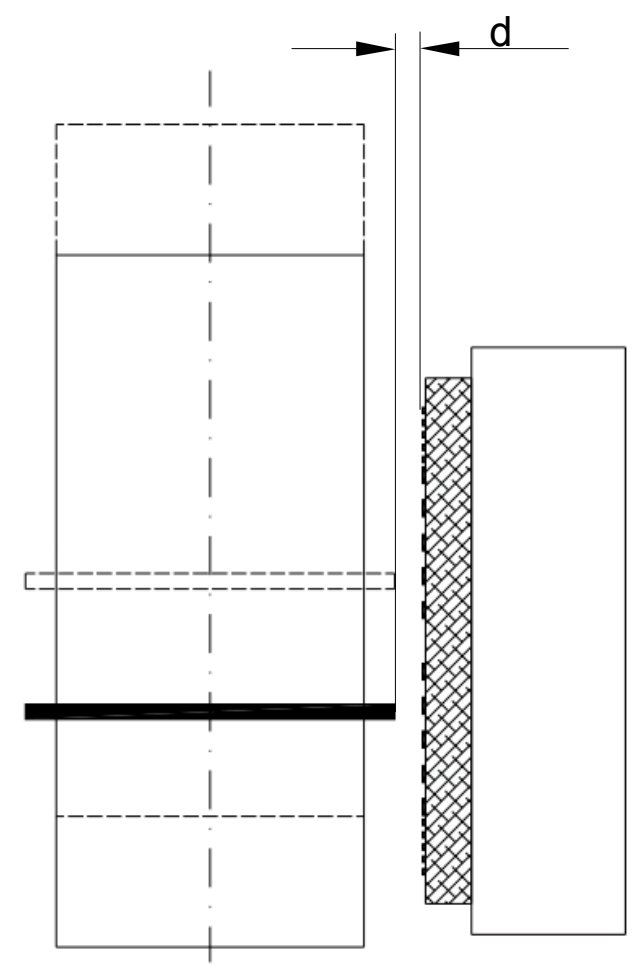

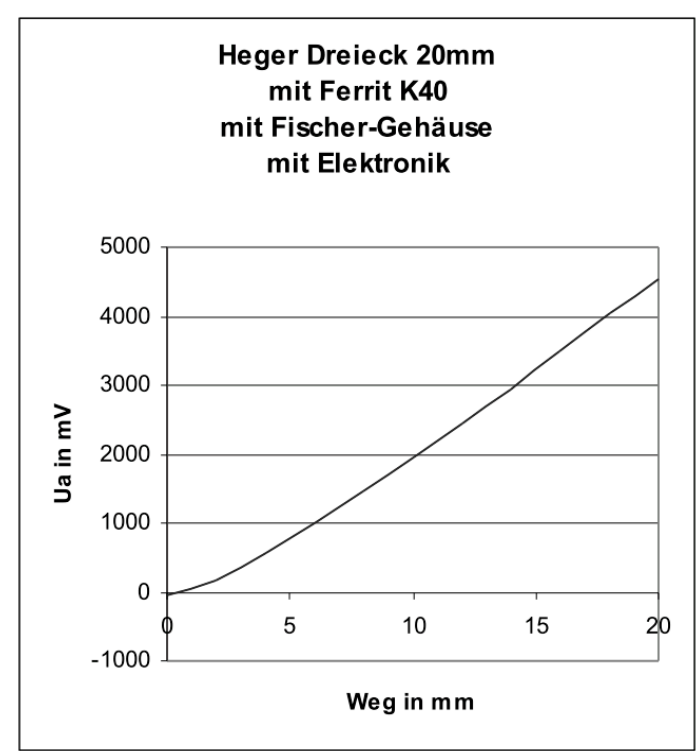

Figur 13: Output voltage dependent on the distance (range $0 \ldots 20 \mathrm{~mm}$ )

Figur 12: Position measuring at a shaft

Also the sensitivity depends on the working distance $d$ of the target (see figure 12 and its characteristic in figure 11). The output amplitude is linear in most part of the characteristic (see figur 13).

The practical results of this device are related to the measuring ranges of $0 . .20 \mathrm{~mm}$ and $0 . .50 \mathrm{~mm}$ for the circuit of figure 5 a. 


\section{Extended Applications}

Angular measurements also can be done by using a configuratioh like in figure 14 . The applied range is between 0 and $150^{\circ}$.

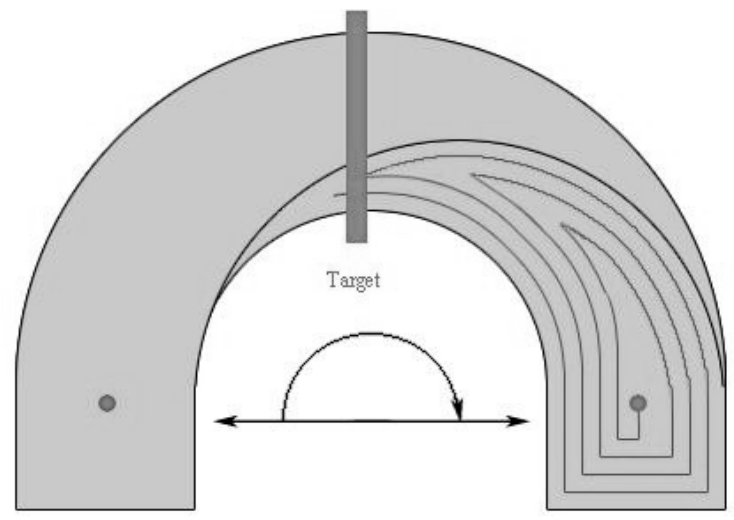

Figur 14: Position sensor for angular measurements

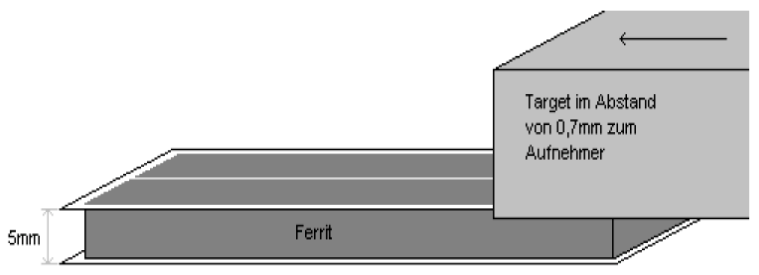

Figur 15: Position sensor for edge measurements

Also the target can be used to do edge measurements, see figure 15. In this application a rectangular coil is used.

The proposed position sensor also can be used for the recognition of coins. In this case the coins have to be transported across the sensor, see figure 16.

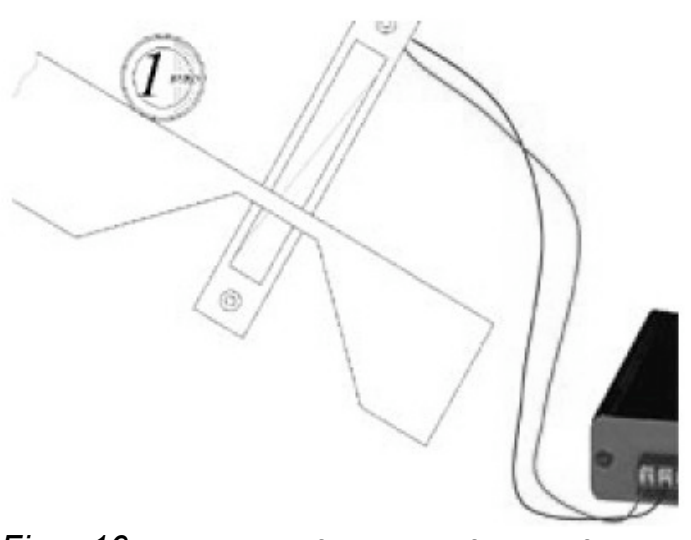

Figur 16: Arrangement for the identifidation of coins

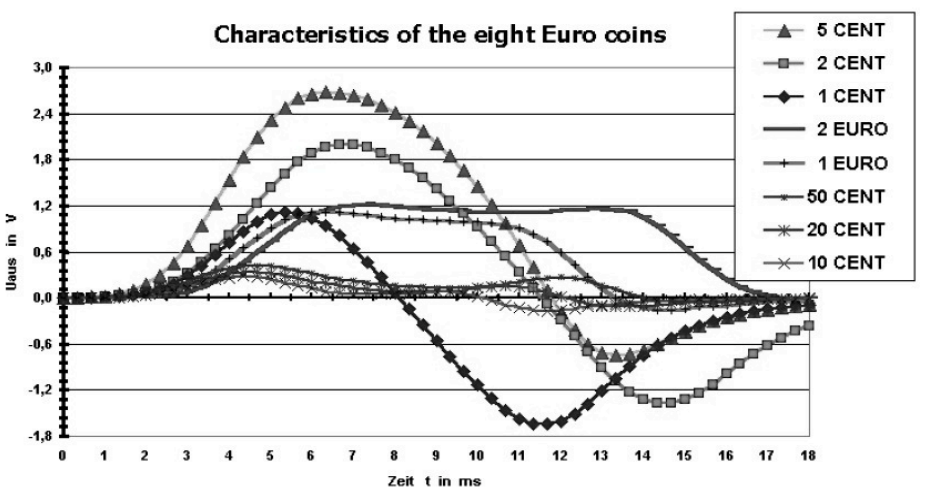

Figur 17: Characteristic signal forms for Euro-coins

The characterstic curves are given in figure 17. The characteristics depend on the diameter of the coins and their material. Also the arrangement of the rolling path of the coins is essential for the form of the outcoming signal (figure 18). The depths of intrusion can be controlled by the working frequeny.

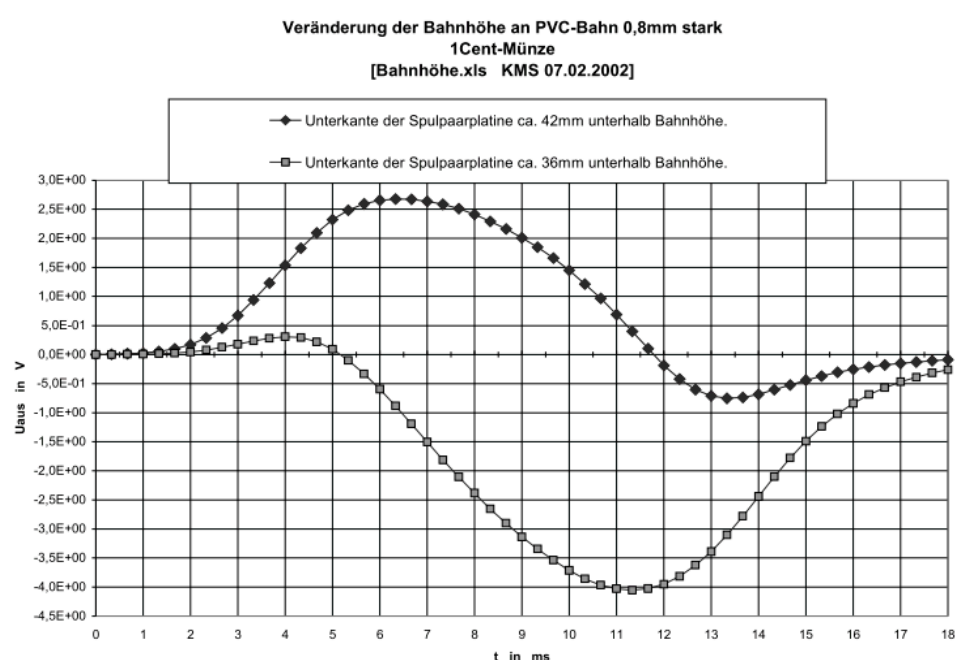

Figur 18: Signal form of 1 Cent coin dependent on the height of the rolling path
The 5 Cent, 2 Cent and 1 Cent coins offer the highest amplitudes. They consist of iron with plated copper and can strongly be magnetized. The $1 €$ and

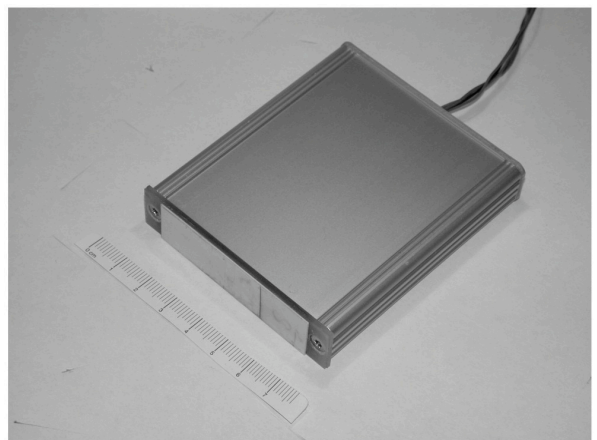

Figur 19: Sensor for recognition of coins with built in electronics 
$2 €$ coins offer medium amplitudes. They consist of nickel-brass and copper-nickel alloys and of nickel. They are weak magnetizable. The 50 Cent, 20 Cent and 10 Cent coins are not magnetizable. They offer the smallest amplitudes.

Figur 19 shows a Sensor for recognition of coins with built in electronics.

\section{Summery}

This position sensor presented here operates without direct contact and has no load influence to the measuring object. It also offers a high and robust reliability because there are no parts of abrasive wear out. The targets may have simple rectangular design. The target material may be magnetic or non magnetic, but has to be calibrated. The high working frequency offers a high speed of operation; $3 \mathrm{kHz}$ have been realisized. Position sensors of this kind also can be applied for the recognition of objets like coins, which are distinguishable by different diameters and materials. The distance between sensor and target has to be constant. It has been demonstrated by several examples that the range of applications is nearly universal.

\section{Literature}

[1] Kindler, Ulrich: $\quad$ Europäische Patentschrift EP 1295089 B 1

[2] Kindler, Ulrich: $\quad$ Mikrosensorik; in Fuhrmann (ed.): Einführung in die Werkstoffkunde und Werkstoffprüfung I, Expert Verlag, 2. Auflage 2008

[3] Nadorow, Andreas.: Entwicklung einer Sensorelektronik mit einseitiger Aussteuerung für die Positionssensoren nach Kindler, Diplomarbeit 2008 Fachhochschule Lübeck

[4] Nadorow, Nicole: Optimierung der Sensorspulen für die Positionssensoren n. Kindler Diplomarbeit 2008 Fachhochschule Lübeck

[5] Kohn, Dietmar: $\quad$ Untersuchung eines induktiven Spiralsensors als Wegaufnehmer und Anwendung des Sensorelementes in Mikroelektronik-Systemen VDI Verlag 1986

[6] Loos, Horst Rudolf: Systemtechnik induktiver Weg- und Kraftaufnehmer, Expert Verlag 1992

[7] Schnell, Gerhard: Sensoren in der Automatisierungstechnik, Vieweg Verlag 1991

[8] Isermann, Rolf: $\quad$ Mechatronische Systeme, Springer Berlin Heidelberg 2008 